\title{
The Different Methods of Displacement Monitoring at Loading Tests of Bridges or Different Structures
}

\author{
Boštjan Kovačič ${ }^{1, a}$, Rok Kamnik ${ }^{1}$ and Andrii Bieliatynskyi ${ }^{2}$ \\ ${ }^{1}$ University of Maribor, Faculty of civil engineering, transportation engineering and architecture, Smetanova 17, SI \\ 2000 Maribor, Slovenia \\ ${ }^{2}$ National Aviation University, Kosmonavta Komarova, 1, Kyiv, 03058, Ukraine
}

\begin{abstract}
By measuring the displacements and deformations at different structures we deal in the Faculty of Civil Engineering, transportation Engineering and Architecture in University of Maribor for about 20 years. At that time we measured over 600 structures. Most loading tests of bridges and Viaducts were made. The measurements of movements needed to be as precise and accurate as possible. To do that laboratory test of instruments were made to see which instrument gives us reliable results. Displacements can be determined by geodetic and physical methods, depends of the construction. The use of geodetic methods are still preferable. In the paper the measurements with the total station, the level and rotation level, photogrammetry and solutions on the field by physical methods with inductive transducers are presented. We need to measure displacements as quick as possible but efficiently because we can not repeat the measurements under the same conditions. Also the surveying on the bridge and in the lab with the comparison of methods is presented under the different hard terrain conditions - water beneath the construction, big height of the structure, unapproachability, large span structures.
\end{abstract}

\section{Introduction}

Scientific discipline test structures and buildings was formed somewhat later than other disciplines in the construction industry. However, some special cases testing facilities exist in very ancient times. The first testing of structures dating back to the XV. century. At the time, Leonardo da Vinci made the first examination of the various forms of construction. The first works and forms of security testing beams were carried out by Galileo in the sixteenth century. He tried to discover the relationship between the impact force to the structure and its budget. At that time was not yet known law of elasticity of the structure, because the dependence set by Galileo Galilei, although it was principally set properly, contained many inaccuracies.

Experimental testing methods of construction in the beginning were based on a theoretical calculation that describes the process of deformation and fracture under the action of the load as described in the book by T. Thomas, 1855 [1]. With the development of numerical science in the last 30 years with the rapid development of information technology, analysis of movements and deformations have dealt with a number of experts who have described their achievements in a number of articles [2-7], and books [8].

\footnotetext{
${ }^{a}$ Corresponding author : bostjan.kovacic@um.si
} 


\section{Displacements and displacements}

Displacements and strains are due to external and internal influences such as wind force, effect of temperature changes, tectonic and seismic effects, changes in the amount of floor (ground) water, static and dynamic loading of objects, say in the form of folds, tilt, turn, distortion of the building, and possible damage in the form of cracks and even fractures [9-12].

Examination of the structure (Fig. 1) or object as a measurement of displacement and strain to determine the change in the position and shape of the building, considering the environment, depending on the time.

Basic indicators for the interpretation of measurement results are character, the direction and magnitude of displacement and strain, and we share in regard to the character in uniform and uneven shifts and the elastic and plastic deformation, in the light of changes in the direction of the horizontal and vertical and considering the size of the non-hazardous, tollerant, serious and critical [13-18].

The measurement of displacement and strain so necessary for assessment of the state of construction, assessment of the state of the object associated with the process of construction or production, or to repair or reinforcement structure and verify the accuracy of theoretical assumptions. The need for experimental testing occurs in the following cases [9]:

- the possibility of using the structure in case of exceeding the useful load,

- testing the durability of construction elements of mass production,

- tests of large and special facilities at the impact of useful load,

- tests of complex systems construction, and testing of its safety.

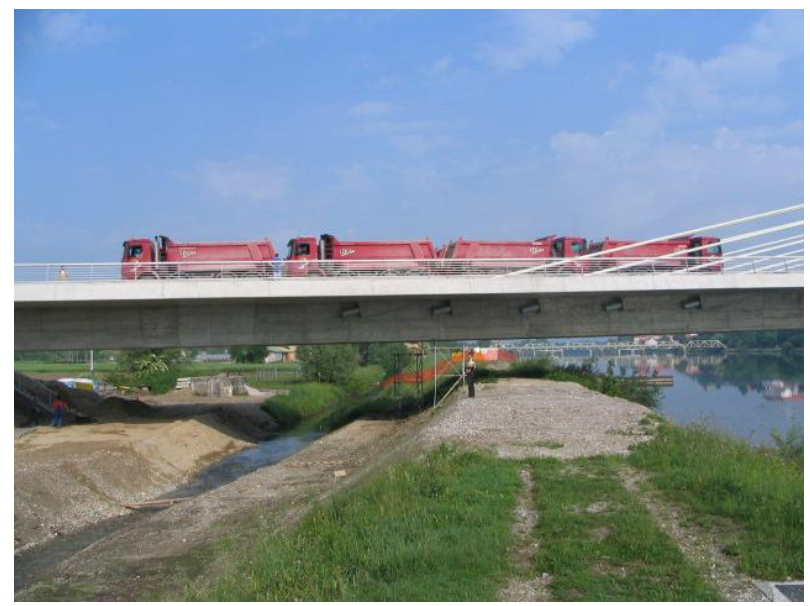

Figure 1. The pilot testing of the bridge

\section{Materials and methods}

\subsection{Methods for displacements measuring}

Vertical movements can measure in different ways and with several methods. What method will be used according to the terms of structures, provided accuracy, planned developments, courts around the structure, external conditions, the number of staff. Displacement measurements usually performed using methods and leveling at higher and higher buildings this method more we can give you results, so we have to use any other surveying method (trigonometry, GPS, photogrammetry ....) or nongeodetic method (measuring inductive the senses, the senses of voltage ...) $[19,20]$

To know which method we should use to know the characteristics of the structure, ie. construction height, length range, which is under construction, scheduled shifts ... 
At the Faculty of Civil Engineering, Transportation Engineering and Architecture, University of Maribor we are sample surveys of bridges and viaducts from 2003. At that time, we conducted more than 300 test trials in Slovenia and abroad. That progress measured the highest accuracy in order to test the method on different structures in the lab and test the bridge [21].

This year we made the test result on the bridge where we used different methods. We used the methods of surveying, leveling method, the method of GPS - RTK method and photogrammetry method trigonometry with three different instruments (traditional total station, station-automatic and robotic cells with built-in scanner), and non-geodetic methods with built-in senses voltage (strain gauge) [22-24].

\subsection{Levelling method}

This method is the oldest method of monitoring progress. So we can get only vertical movement and high accuracy.

Leveling is so well-known methods and the most used. In this method needs to be mindful that we have a point that is used for comparison to the field where we do not have a fixed displacement and strain so most times stabilize the bridge where there is no cargo and no oscillations (Figure 2).

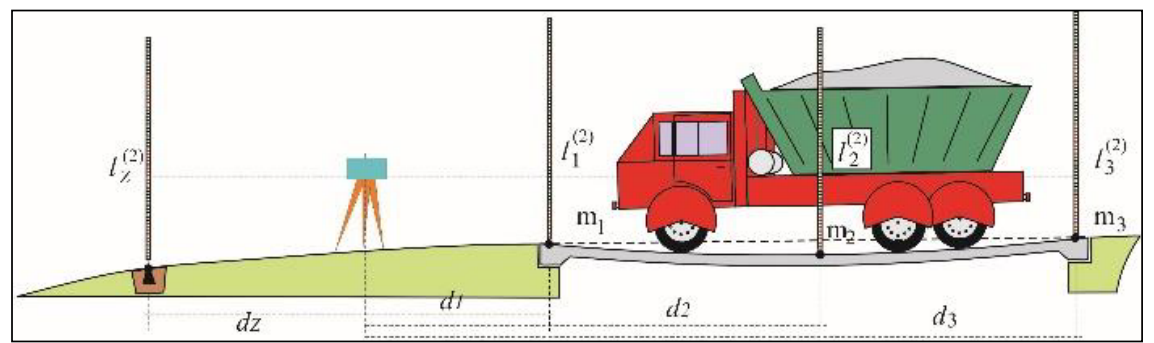

Figure 2. An example of leveling the reference points outside the structure

The problem of this method is the construction of a large range. Thus, the method should be leveled leveling the middle there and back. It takes us a long time. It's the same problem with the construction of a large harbor. So that this method has meaningfully used in smaller structures (bridges over highways or smaller rivers). In Figure 3 we can see a small overpass Pekel near Maribor who has been tested and leveling.

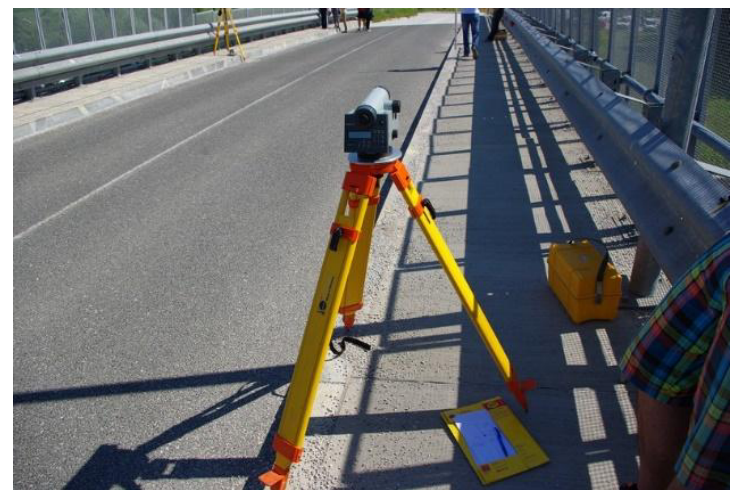

Figure 3: Levelling the overpass Pekel near Maribor.

In practice, with small bridges can be used and leveling rotary laser with sensors that are attached to your computer. This method can be used and the dynamic tests. 


\subsection{Method of trigonometry}

The method of trigonometry are the most useful. With this method, we can measure progress in greater lengths and heights of the structure. To obtain high precision measurements should be made in several gyms that are in traditional total station takes too much time. Recently, using the robotic total station where during one gyrus measuring classical instruments make 3 gyrus. In this way we get more data from which we can calculate the precise measurement and an ellipse of errors. It is important at the micro-shift, where shifts in the range of accuracy of the instrument because using robotic cells with $0.5 \mathrm{sec}$ possibility of measuring angles $[25,26]$.

Practice has shown us, that the best method to use trigonometry using electronic tachymeter with which we can measure the length and vertical angle. With the import of meteorological conditions, the measured length and angle calculations with coordinates or new item or change in terms of height. Based on the height of trigonometry and import of all parameters and error can be calculated using the change in H-known formula [10][12]:

$$
\Delta H=S \cdot \operatorname{ctg} Z_{A}+i_{A}-l_{B}+\left(\frac{1-k_{a}}{2}\right) \cdot\left(\frac{S^{2}}{R}\right)+\omega
$$

where is:

$S$ - Length

$\mathrm{Z}_{\mathrm{A}}$ - vertical angle

$\mathrm{i}_{\mathrm{A}}$ - the height of the instrument at point $\mathrm{A}$

$1_{B}$ - Reflector height at point $B$

$\mathrm{k}_{\mathrm{a}}$ - the coefficient of refraction (for Slovenia to $\mathrm{f}=0.13$ )

$\mathrm{R}$ - radius of the Earth

$\omega$ - correction coefficient

The method of trigonometric leveling, which is used in pilot testing of structures, that is what affects the results. For each measure it is necessary to pre-calculate the accuracy of the measurement, which is based on the classic geodetic works where the height difference obtained by the above formula.

In the pilot tests and the measurement of vertical movement can of formula 1 drop height of the instrument and $\mathrm{A}$, as measured in the relative coordinate system and the local system. From the formula we can drop and reflector height $b$, because we are, lock the retro brand and using the height of $0.0 \mathrm{~mm}$. The measured lengths were relatively short $(\mathrm{S}<150 \mathrm{~m})$ and we dropped a correction due to the curvature of the Earth.

Thus, formula 1 can be written in another form [11],[12]:

$$
\Delta H_{a}=S \cdot \operatorname{ctg} Z_{A}+\frac{S^{2}}{2 R}-k_{a} \frac{S^{2}}{2 R}
$$

In our example replaces the zenith length of the vertical angle and the length of the hair, so the formula is:

$$
\Delta H_{a}=D_{p} \cdot \sin \alpha+\frac{D_{p}{ }^{2}}{2 R}-k_{a} \frac{D_{p}{ }^{2}}{2 R}
$$

For variable size can take the length $\mathrm{Dp}$, vertical angle and refraction coefficient $\mathrm{k}$.

With this formula, we can get very precise vertical movement. Also this method gives us the ability to measure shifts in the direction of $\mathrm{x}, \mathrm{y}$, so that we get shifts in the $3 \mathrm{D}$ direction of what we used in the monitoring of movements and deformations of the stairs and dams and most of geodetic monitoring of the 3D direction. In Figure 4, we see two positive tools for proof testing Pekel overpass near Maribor. 


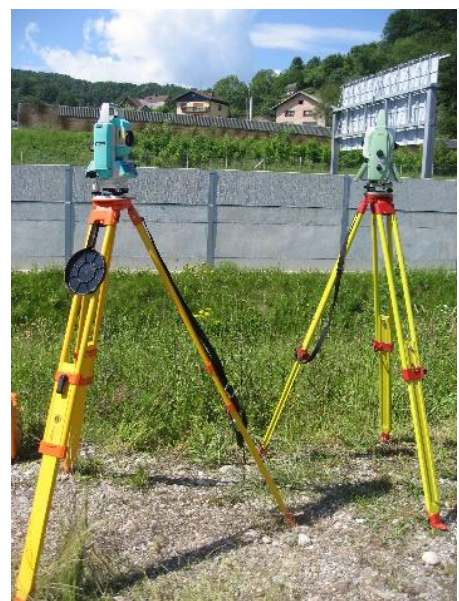

Figure 4: Two total station next to the overpass Pekel

In our example, the testing instrument for monitoring the progress we used a total station Nikon NPL series 352 and robotic station LEICA MS50.

Table 1 shows the resulting shifts in the point T1 in the middle of the range 1 and T2 in the middle of the range 2 with both instruments. With a classical station we made a survey in one gyrus with a robotic station in 5 gyrus. From the results it can be seen and the accuracy of the Leica total station with classical instrument from one gyrus, we can not get accurate measurements so that in this example uses the accuracy of the instrument.

Table 1. Comparison of the measurement results

\begin{tabular}{|c|c|c|c|c|}
\hline & \multicolumn{4}{|c|}{ Vertical displacements [mm] } \\
\hline Point & \multicolumn{2}{|c|}{ Phase 1 } & Phase 2 \\
\hline & NPL & MS50 & NPL & MS50 \\
\hline T1 & -2.0 & -1.8 & 0.5 & 0.3 \\
\hline T2 & 1.0 & 1.8 & 2.0 & -2.7 \\
\hline
\end{tabular}

\subsection{Scanning Method}

Lately there is much talk about field scanners. By now we know the classic scanner and the company made a LEICA instrument Multi Station, which is a combination of robotic cells, and scanners with the precision of sight $0.5 \mathrm{l}$. With this instrument, we also measured the progress in the construction of the test 3 gyrus and in the same time and make a scan at the time of construction, without load and when we put the load as seen in Figures 5, 6. With the structure we obtain the image scan to the coordinate system and gain a complete model of the structure that we used for different simulations.

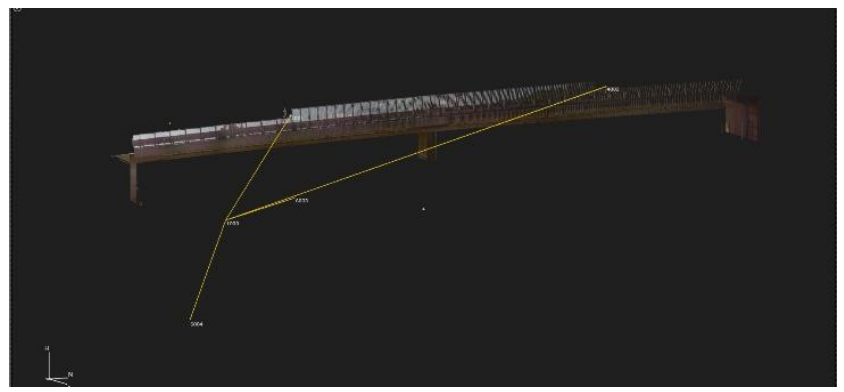

Figure 5. Overpass Pekel and measurement points - an empty object (scan) 


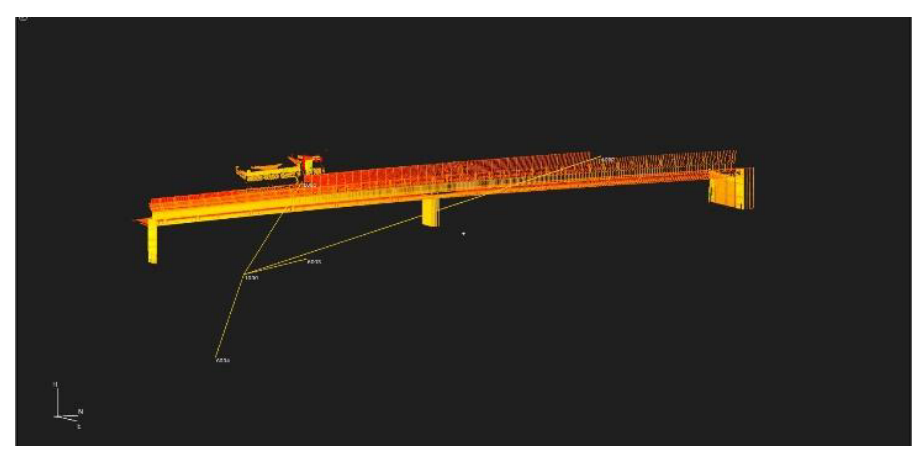

Figure 6. Overpass Pekel - loaded object (scan)

We can also get the mathematic comparison image and shifts for each point of the structure. It gives us a whole picture of structural behavior during load. Certainly this method is accurate and effective. Just to make structural model in office it would take several days and there we get in a few minutes the entire model.

\subsection{GPS method}

Global Positioning System (GPS) is recently used increasingly for testing. Surveyors use it for recording terrain, positioning objects ... We also tested the GPS to track vertical movement. We used the method of RTK and every 5 seconds made a survey (Figure 7). I need to know, that the accuracy of GPS in the range from a few millimeters to a few centimeters so that this method can not get a shift rank 1-3 mm. After analyzing the results, we get the shift level $12 \mathrm{~mm}$ which is more than all the other results obtained with other instruments. GPS method is mostly used for geodetic monitoring of landslide where the antenna is left in the same place for 24 hours, and we use the statics readings every 15 seconds.

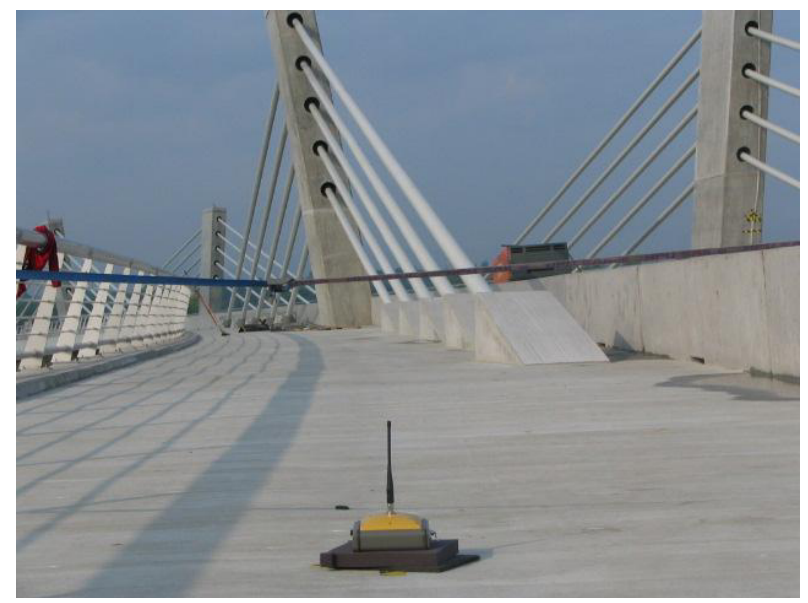

Figure 7. GPS device on Puchov bridge in Ptuj

\subsection{Method of photogrammetry}

For comparison measurement method shifts we used and the method of stereo-photogrammetry. In this method we use brand - points that are fixed in the vicinity of geodetic mark, so the comparisons shift (Figure 8). 


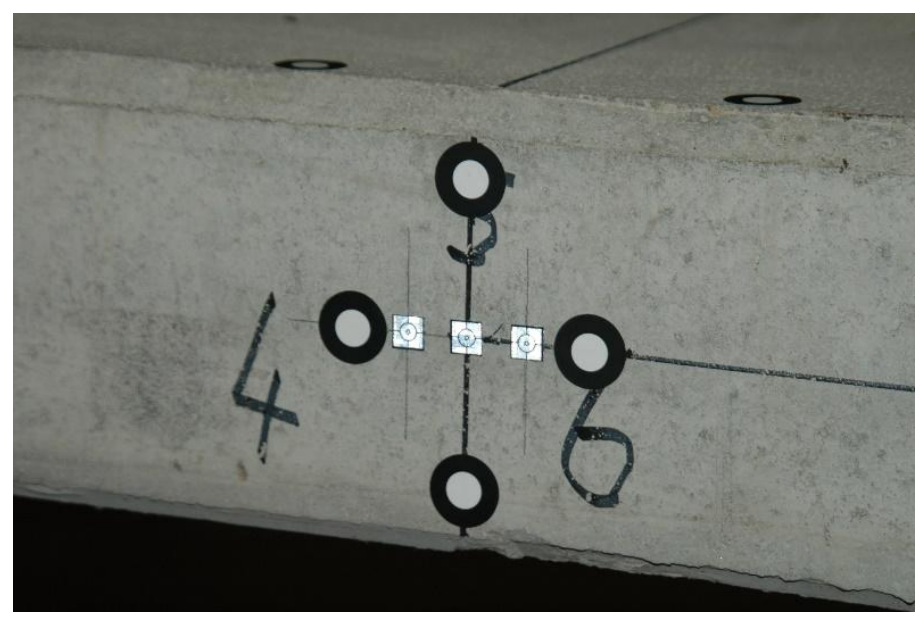

Figure 8. Self-adhesive retro brand

Mark - point is the white circle with a diameter of $18 \mathrm{~mm}$ on a black background. It is used a system for stereo-photogrammetry TRIPOP manufacturer $\mathrm{GmbH}$ (Braunschweig, Germany), in which the CCD camera Fuji S3 Pro with a resolution of 4256 × 2848 pixel and a software package for the analysis of the object coordinates. In every step of the load was made at least 8 shots at different angles and positions and, most importantly, the images should mind all brands. Photos of individual phase loads are processed with software. The results of processing the motion vector in the vertical direction (Figure 9). The maximum standard deviation results in each phase was $0.08 \mathrm{~mm}$.

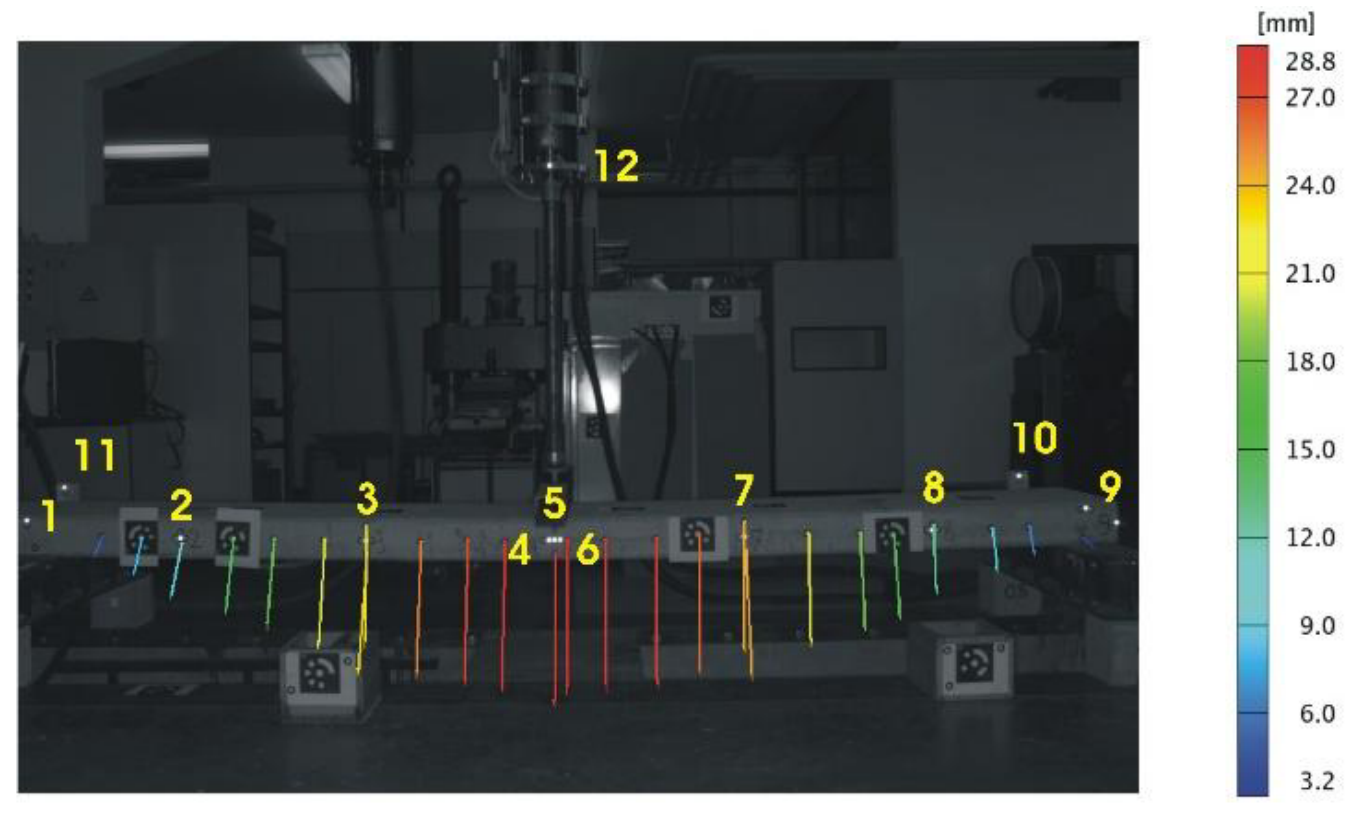

Figure 9. Displacement vectors

Photogrammetry method is used for smaller construction and testing in the laboratory. For large structural problem resolution photos and positions with which we make shots, because we do not see all stamps from the point. 
By these methods, most use inductive felt we put under construction. These sensors are highly sensitive and provide us with the most accurate results. We use them in the dynamic tests where the geodetic methods can not be so quick to make the recording points.

Gauging - strain gauge can be put on the reinforcement of the bridge already at the time of construction or glued to the structure when it is already built. Gauging give us the results of the specific deformations in terms of voltage change in the material. When building the largest viaduct in Slovenia - Crni Kal - we placed our over 100 papers, and at the time of load track and structural behavior change specific strain.

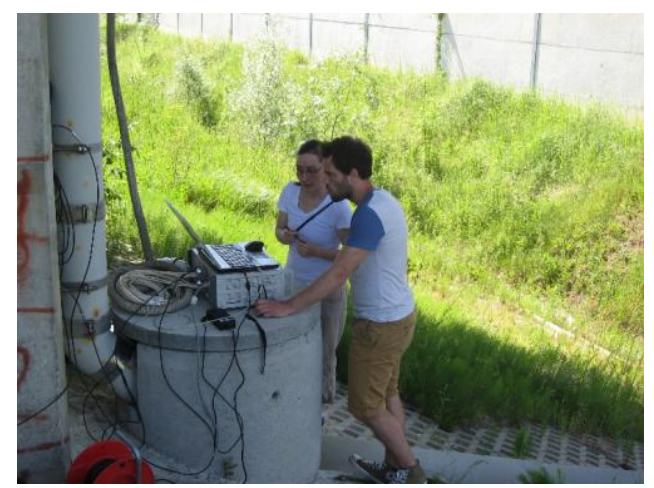

Figure 10. Measurements of voltage below the overpass Pekel

\section{Comparison of results and discussion}

In preliminary tests structure we used different methods. Before you do the test should see what is the structure, which has beneath it, which rank shift predict and range structure. Based on that we decide which method we use. In practice, it's always good to use two methods at the same time so that we can make analysis and comparison. You need to know that with geodetic methods can not make repeated measurements under the same conditions, so you should be very careful in measuring and concentrated.

Results of the test tests gave us some answers about the accuracy of the measurements. From the results it can be seen that the improvements obtained with different methods on the same level with a margin of a few tens of $\mathrm{mm}$. For such a small structure is sufficient to use inductive sense for the dynamic portion of the test and the method of leveling, for larger structures and robotic cell with or without scanner and inductive measuring senses and leaves.

\section{Conclusion}

Observation of the structure under load can be performed in various ways, as described by many authors. Which method will be used mainly depends on the range of construction, planned developments, access to the construction and weather conditions. In practice, it makes sense to use at least two independent methods which we partially increases costs and increases measurement time, but can provide us with more reliable results. On the basis of multiple measurements can be performed by a variety of statistical analyzes and comparisons.

In our case, we used seven different methods. The aim of the measurements was to compare and determine the most appropriate method. If you can already in the construction phase set Gauging it would be most appropriate as we get some amount (as happens with the structure, temperature, stretch material ...) during construction. Other surveying methods are used for the static portion of the test. From the test examination we see that without surveying can not carry out trial tests. 


\section{References}

1. T. Thomas. Principles of geometry, mensuration, trigonometry, land-surveying and levelling (Longman, London, (1855)

2. M. Tatin, M. Briffaut, F. Dufour, A. Simon, J.-P. Fabre, Engineering Structures, 91, 26-39 (2015).

3. J. Yu, X. Meng, X. Shao, B. Yan, L. Yang. Engineering Structures, 81, 432-443 (2014)

4. N. Vatin, N. Lavrov, A. Shipilov, Procedia Engineering, 117 (1), 374-380 (2015)

5. C. Almeida Santos, C. Oliveira Costa, J. Batista. Mechanical Systems and Signal Processing, In Press, (2015)

6. S. Ognjenovic, Z. Krakutovski, N. Vatin, Procedia Engineering, 117 (1), 564-572 (2015)

7. S. Ognjenovic, R. Donceva, N. Vatin, Procedia Engineering, 117 (1), 556-563 (2015)

8. M. Dilena, M.P. Limongelli, A. Morassi, Mechanical Systems and Signal Processing, 52-53, 162-180 (2015)

9. C. Venkatramaiah, Textbook of Surveying (Orient Blackswan, London, (2011)

10. B. Kovačič, R. Kamnik., M. Premrov. Survey Review, 43 (320), pp. 150-161 (2011)

11. Vodopivec, F. The precise leveling (Ljubljana, FUJ (1988)

12. B. Kovačič, R. Kamnik. AVN. Basic Vermessungs messages, 113, 10, p. 322-329 (2006)

13. Marendic A., Z. Kapovic, R. Paar, Geodetski list, 3, 175-190 (2013)

14. Z.Popović, L. Lazarevic, N. Vatin, Procedia Engineering, 117 (1), 846-853 (2015)

15. S. Ognjenovic, R. Ristov, N. Vatin, (2015) Procedia Engineering, 117 (1), 575-578 (2015)

16. S. Rutešić, J. Ćetković, M. Žarcković, M. Knežević, N. Vatin, Procedia Engineering, 117 (1), 905-915 (2015)

17. S. Ognjenovic, Z. Zafirovski, N. Vatin, Procedia Engineering, 117 (1), 579-584 (2015)

18. S. Popović, S. Vlahović, N. Vatin, Procedia Engineering, 117 (1), 854-863 (2015)

19. S. Rutešić, J. Ćetković, M. Knežević, M. Žarcković, N. Vatin, Procedia Engineering, 117 (1), 642-650 (2015)

20. R. Usmanov, I. Mrdak, N. Vatin, V. Murgul, Applied Mechanics and Materials, 633-634, 932-935 (2014)

21. R. Usmanov, V. Murgul, N. Vatin, Applied Mechanics and Materials, 633-634, 1082-1085 (2014)

22. R. Usmanov, M. Rakočević, V. Murgul, N. Vatin, Applied Mechanics and Materials, 633634, 927-931 (2014)

23. V.V Okrepilov, M.V. Leonidovich, Asian Social Science, 11 (7), 312-325 (2015)

24. I. Mrdak, M. Rakočević, L. Žugić, R. Usmanov, V. Murgul, N. Vatin, Applied Mechanics and Materials, 633-634, 1069-1076 (2014)

25. V.V Okrepilov, V.L. Makarov, A.R. Bakhtizin, S.N Kuzmina, Economy of Region, 2, 301$313(2015)$

26. V.L. Kvint, V.V Okrepilov, Herald of the Russian Academy of Sciences, 84 (3), 188-200 (2014) 